\title{
Fibrinogen Early In Severe Trauma studY (FEISTY): results from an Australian multicentre randomised controlled pilot trial
}

James Winearls, Martin Wullschleger, Elizabeth Wake, Zoe McQuilten, Michael Reade, Catherine Hurn, Glenn Ryan, Melita Trout, James Walsham, Anthony Holley, Shane George, Wayne Dyer, James McCullough, Gerben Keijzers, John Fraser, Jeffrey Presneill and Don Campbell

Despite advances in trauma management over the past decade, haemorrhage in the setting of severe trauma remains a major cause of morbidity and mortality. ${ }^{1-4}$ Death related to haemorrhage is potentially preventable and represents a target for mortality reduction strategies. Traumatic haemorrhage is complicated by trauma-induced coagulopathy (TIC) - a complex clinical syndrome for which the pathophysiological mechanisms are not completely understood. ${ }^{5-7}$

Fibrinogen plays a critical role in maintaining effective haemostasis in traumatic haemorrhage and TIC. ${ }^{8-11}$ Hypofibrinogenaemia and increased fibrinogen breakdown are key elements of TIC and fibrinogen is usually the first factor to reach critically low levels in traumatic haemorrhage. ${ }^{12,13}$ Hypofibrinogenaemia after severe trauma is associated with increased risk of massive transfusion and death. ${ }^{14-18}$ it has been postulated that early fibrinogen replacement may assist in haemorrhage control, correct coagulopathy and reduce transfusion requirements. ${ }^{16,19,20}$ Recently published trauma guidelines suggest fibrinogen replacement when plasma fibrinogen levels are $<1.5-2.0 \mathrm{~g} / \mathrm{L}$ or when there are thromboelastometric signs of fibrinogen deficiency. ${ }^{21}$

Fibrinogen can be replaced with fresh frozen plasma (FFP), cryoprecipitate (Cryo) or fibrinogen concentrate (FC), which contain different concentrations of fibrinogen

\section{ABSTRACT}

Background: Haemorrhage is a major cause of death in severe trauma. Fibrinogen plays a critical role in maintaining haemostasis in traumatic haemorrhage, and early replacement using fibrinogen concentrate (FC) or cryoprecipitate (Cryo) is recommended by several international trauma guidelines. Limited evidence supports one product over the other, with widespread geographic and institutional variation in practice. Two previous trials have investigated the feasibility of rapid FC administration in severely injured trauma patients, with conflicting results.

Objective: To compare the time to fibrinogen replacement using FC or Cryo in severely injured trauma patients with major haemorrhage and hypofibrinogenaemia.

Design, setting, patients and interventions: A multicentre controlled pilot trial in which adult trauma patients with haemorrhage were randomly assigned (1:1) to receive FC or Cryo for fibrinogen replacement, guided by FIBTEM A5 (functional fibrinogen assessment at 5 minutes after clot formation, using rotational thromboelastometry).

Main outcome measures: The primary outcome was time to commencement of fibrinogen replacement. Secondary outcomes included effects of the intervention on plasma fibrinogen levels and clinical outcomes including transfusion requirements and mortality.

Results: Of the 100 randomly assigned patients, 62 were hypofibrinogenaemic and received the intervention $(n=37)$ or Cryo $(n=25)$. Median (interquartile range [IQR]) time to delivery of FC was 29 min (23-40 min) compared with 60 min (40$80 \mathrm{~min})$ for Cryo $(P=0.0001)$. All 62 patients were hypofibrinogenaemic before receiving $\mathrm{FC}$ or Cryo (FC: median FIBTEM A5, 8 mm [IQR, 7-9 mm]; Cryo: median FIBTEM A5, $9 \mathrm{~mm}$ [IQR, 5-10 mm]). In the $\mathrm{FC}$ arm patients received a median of $3 \mathrm{~g}$ FC (IQR, 2-4 g), and in the Cryo arm patients received a median of 8 units of Cryo (IQR, 8-14 units). Restoration of fibrinogen levels was achieved in both arms after the intervention. Blood product transfusion, fluid resuscitation and thromboembolic complications were similar in both arms. Overall mortality was $15.3 \%$, with more deaths in the FC arm.

Conclusion: Fibrinogen replacement in severely injured trauma patients with major haemorrhage and hypofibrinogenaemia was achieved substantially faster using FC compared with Cryo. Fibrinogen levels increased appropriately using either product. The optimal method for replacing fibrinogen in traumatic haemorrhage is controversial. Our results will inform the design of a larger trial powered to assess patient-centred outcomes. 


\section{ORIGINAL ARTICLES}

(2 g/L, 8-16 g/L and $20 \mathrm{~g} / \mathrm{L}$, respectively). The low concentration of fibrinogen in FFP and the large volumes required potentially make FFP unsuitable for dedicated fibrinogen replacement. ${ }^{22-24}$ The results of the RETIC (reversal of trauma-induced coagulopathy using first-line coagulation factor concentrates or fresh frozen plasma) trial, which compared FFP to factor concentrate-based resuscitation in trauma patients, suggest the importance of early fibrinogen replacement and potentially the superiority of factor concentrates. ${ }^{25}$ Cryo contains substantially higher concentrations of fibrinogen than plasma and is widely accepted as the standard of care for fibrinogen replacement in haemorrhage. ${ }^{26,27}$ In addition, Cryo contains several other coagulation factors that are not in FC. ${ }^{28}$ The CRYOSTAT 1 trial showed that early fibrinogen replacement using Cryo was feasible and effectively maintained fibrinogen levels in traumatic haemorrhage. ${ }^{29}$ Using large doses of Cryo in traumatic haemorrhage can put strain on local blood banks in terms of supplying requested units in a timely manner. Also, widely dispersed populations of some regions, such as parts of Australia and Canada, introduce logistic challenges to maintaining adequate Cryo stocks for individual hospitals. FC has several theoretical advantages, including: standard dose per vial, reduced volume, viral inactivation, no requirement for $A B O$ compatibility matching, long shelf life (60 months at $2-8^{\circ} \mathrm{C}$ ), and ease of transport, reconstitution and administration. However, at present, FC in comparison to Cryo is not supported by good evidence. ${ }^{30}$ Two recently published trials investigating early empiric use of FC in traumatic haemorrhage reported opposing results. The Canadian FiiRST trial (Fibrinogen in the Initial Resuscitation of Severe Trauma) reported that early FC administration was feasible, whereas the British E-FIT 1 trial (Early Fibrinogen Concentrate Therapy for Major Haemorrhage in Trauma) found the opposite. ${ }^{31,32}$ In addition, in severe trauma there are no robust clinical trials that show any survival or health economic benefit for FC compared with Cryo. 9,24,33

Several key questions regarding fibrinogen replacement in traumatic haemorrhage remain unanswered, including:

- What tests, if any, should be used to guide fibrinogen replacement?

- What is the optimal product for fibrinogen replacement?

- What is the optimal dose of fibrinogen?

- What is the impact of early fibrinogen replacement on clinically important outcomes?

We conducted the Fibrinogen Early In Severe Trauma studY (FEISTY) randomised controlled pilot trial to assess the feasibility of early fibrinogen replacement using FC compared with Cryo in patients with traumatic haemorrhage and viscoelastic evidence of hypofibrinogenaemia. We aimed to determine whether fibrinogen replacement to reverse hypofibrinogenaemia could be achieved more rapidly using FC compared with Cryo and provide information for designing a more definitive trial.

\section{Methods}

FEISTY was an investigator-initiated, multicentre, randomised controlled, pilot trial comparing FC with Cryo for fibrinogen replacement in traumatic haemorrhage. It was conducted in four major trauma centres in Queensland, Australia, between December 2016 and September 2017. The trial was prospectively registered on ClinicalTrials.gov (NCT02745041). A full trial protocol has previously been published. ${ }^{34}$

\section{Eligibility criteria and randomisation}

Adult trauma patients (aged $\geq 18$ years) were eligible for enrolment if judged by treating clinicians to have clinically significant haemorrhage or potential for significant transfusion requirements with an assessment of blood consumption $(A B C)$ score of $\geq 2.35,36$ Patients were excluded if: they had injuries deemed incompatible with survival; they had received prior fibrinogen replacement (either FC or Cryo); greater than 6 hours had elapsed between injury and presentation; they had a known objection to blood product transfusion; they had a known coagulation disorder; they were known to be pregnant; or they were enrolled in a competing trial.

Patients were randomly assigned to an intervention arm (1:1) using a block randomisation schedule produced by a statistician independent to the study, accommodating the possibility of unequal patient recruitment across the four sites. Secure, password-protected, web-based randomisation occurred on patient arrival to the trauma unit. Patients subsequently received protocol-directed FC or Cryo replacement. Allocation concealment was maintained through to the conclusion of the web-based randomisation process but, for practical and safety reasons, patients and their treating health care professionals were not blinded to the trial intervention. Trial integrity was supported by maintenance of blinding for outcome assessors and the trial statistician.

\section{Ethics approval and consent to participate}

Multisite ethics approval for the study was granted by the Gold Coast Hospital and Health Service Human Research Ethics Committee (HREC/16/QGC/128). Where possible, informed consent was obtained from trial patients. In the setting of severe trauma and especially as the intervention was time critical, this was not always possible. When this was the case, consent was sought from available next of kin. If no next of kin were available, emergency research processes were followed, allowing enrolment into the trial 


\section{ORIGINAL ARTICLES}

with agreement of a senior clinician. Consent to continue was subsequently sought from the patient or next of kin as soon as possible.

\section{Intervention}

Patients were randomly assigned to receive fibrinogen replacement using FC (RiaSTAP, CSL Behring GmbH, Marburg, Germany) or Cryo (whole blood or apheresis Cryo) (Australian Red Cross Lifeblood). The requirement for fibrinogen replacement was defined by a FIBTEM A5 $\leq 10 \mathrm{~mm}$ with a clinical scenario suggesting significant haemorrhage. ${ }^{37}$ The FIBTEM assay is a functional fibrinogen assessment using a rotational thromboelastometry device (ROTEM Sigma, Werfen, Spain), and A5 is the clot amplitude 5 minutes after initial clot formation. ROTEM assesses clot formation, strength and lysis by measuring the rotational force that is transmitted to an electromechanical transducing system by formation of a clot, which is displayed graphically and numerically. Participating sites had experience with ROTEM-guided transfusion before trial commencement. ${ }^{38}$ The intervention was administered to randomly assigned patients as soon as possible after FIBTEM analysis indicated that fibrinogen was required. Patients remained in their allocated intervention arm for the duration of their hospital admission up to 30 days. FC and Cryo dosing were guided by the FIBTEM A5 result as per the trial protocol (Figure 1).34 The dosing strategy was developed based on published and institutional data and in consultation with Australian Red Cross Lifeblood; assuming that $1 \mathrm{~g}$ of fibrinogen replacement (FC or Cryo) will result in an increment of $1-2 \mathrm{~mm}$ in the FIBTEM assay or $0.25 \mathrm{~g} / \mathrm{L}$ using the Clauss fibrinogen (FibC) assay, and to achieve a $1 \mathrm{~g}$ dose of fibrinogen replacement, 3-4 units of whole blood Cryo will be required. ${ }^{29,39-43}$ FC was administered by rapid intravenous injection and Cryo by rapid intravenous infusion. Fibrinogen replacement was continued throughout the resuscitation according to the protocol and as per the allocated intervention arm (Figure 1).

All other care received by trial patients was prescribed by the treating clinicians according to relevant local hospital clinical and trauma guidelines, based on the principles of damage control resuscitation.

\section{Outcome measures}

The primary outcome was the time interval in minutes from blood draw for FIBTEM analysis to the commencement of first administration of fibrinogen (FC or Cryo). In both arms, the aim was to administer fibrinogen replacement within 30 minutes of fibrinogen requirement being identified. Consistent with the exploratory nature of this pilot trial, we evaluated multiple secondary outcomes: (i) effects of fibrinogen replacement (FC and Cryo) on plasma fibrinogen levels (FIBTEM A5 and FibC); (ii) time course of fibrinogen levels as measured by FIBTEM A5 and FibC; (iii) transfusion requirements (all blood products) in the first 24 hours of hospital admission and for the entire hospital admission; (iv) clinically relevant thromboembolic complications during hospital admission; and (v) mortality at 90 days.

\section{Sample and data collection}

Several blood tests to assess haemostasis were performed at pre-defined time points from admission to Day $7 .{ }^{34}$ Arterial blood gas analysis was performed on admission and as clinically indicated. Blood chemistry tests assessing organ function were performed at the discretion of treating clinicians. Patient characteristics, mechanism of injury, and data on pre-hospital and on-admission physiological variables were collected. Data regarding injury severity and degree of critical illness were collected and scored using the injury severity score (ISS) and APACHE (Acute Physiology and Chronic Health Evaluation) II score. Timing and volume of blood product transfusion and administration of tranexamic acid were recorded. Specifically, volume of Cryo was recorded as number of whole blood units of Cryo (where 1 unit of apheresis Cryo is equal to about 2 units of whole blood (ryo). Patients were followed up at 30 and 90 days.

\section{Sample size and statistical analysis}

Details of the sample size and statistical analysis plan have previously been published. ${ }^{34}$ Briefly, the pilot trial sample size of 100 patients (allocated 1:1 to FC or Cryo) was based on estimated recruitment rates across four sites and influenced by the available budget. Although patients were randomly assigned to the FC or Cryo arm, administration of fibrinogen depended on abnormal FIBTEM, with a clinical scenario suggesting significant haemorrhage. Thus, by design, the trial primary outcome and related secondary outcomes are reported for the per-protocol set of patients, ${ }^{44}$ defined as those patients administered at least one dose of FC or Cryo. Where appropriate, other analyses used the conventional intention-to-treat cohort - all randomly assigned patients for whom consent was available.

Baseline variables were summarised using descriptive statistics. The primary outcome and other time-to-event outcomes are displayed as Kaplan-Meier curves, compared between treatments using a log-rank test, and summarised using the Kaplan-Meier estimated median time to event. ${ }^{34}$ All normally distributed continuous variables were compared using $t$ tests, and the remaining variables were compared using non-parametric (Mann-Whitney) methods. The differential trajectories over time of fibrinogen levels according to intervention - before and after the first dose of FC or Cryo and, separately, over the first 7 days - were 
Figure 1. Intervention and dosing strategy

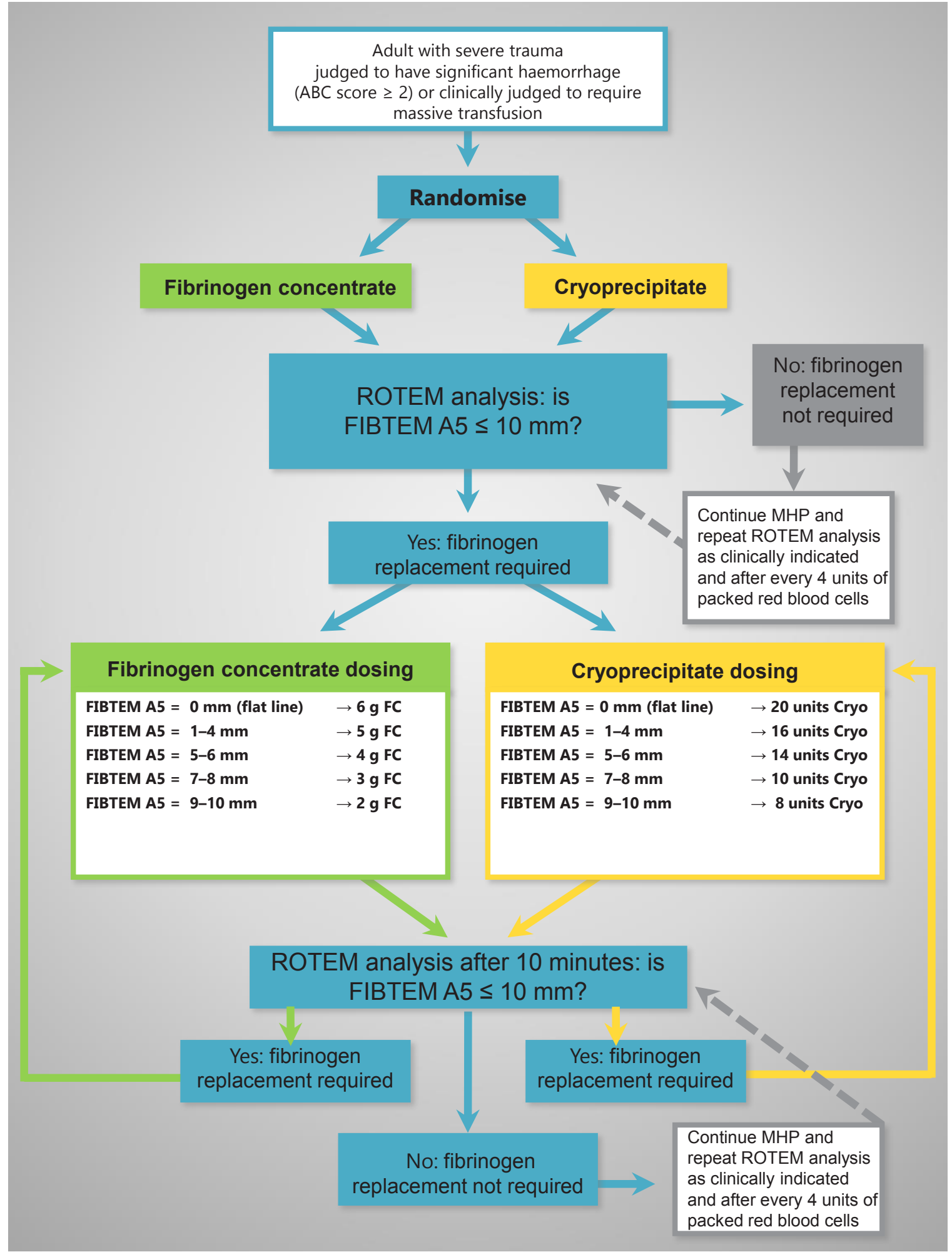

$A B C=$ assessment of blood consumption. Cryo $=$ cryoprecipitate. $F C=$ fibrinogen concentrate. FIBTEM A5 = functional fibrinogen assessment at 5 minutes after clot formation. $\mathrm{MHP}=$ major haemorrhage protocol. $\mathrm{ROTEM}=$ rotational thromboelastometry. 


\section{ORIGINAL ARTICLES}

assessed within linear regression models using a generalised estimating equation approach incorporating robust error estimates to account for within-subject correlation of fibrinogen levels over time. ${ }^{45}$

An independent data and safety monitoring committee (DSMC) blinded to the randomisation data monitored results of the trial and patient safety data. All serious adverse events were evaluated and classified independently by the co-chief investigators, and any disagreements were resolved by consensus. The DSMC planned to conduct two equally spaced interim analyses, at one-third $(n=33)$ and two-thirds ( $n=67$ ) of recruitment, to assess the differential proportions of all-cause hospital mortality (censored at 30 days for practical reasons). These interim analyses followed a group sequential plan employing symmetrical, twosided, Haybittle-Peto three-standard-deviation thresholds to evaluate a standardised test statistic $\left(\left|Z_{k}\right| \geq 3\right)$ calculated from a normal approximation to the discrete binomial difference observed between treatment and control groups in mortality. In practice, the trial recruited rapidly, with the first 30-day follow-up interim analysis being the only one completed and reviewed by the DSMC before recruitment completion. The manuscript was produced according to CONSORT recommendations for reporting randomised clinical trials.

\section{Results}

\section{Recruitment and patient characteristics}

Between December 2016 and September 2017, 114 adult trauma patients with major haemorrhage were identified

\section{Figure 2. CONSORT diagram for FEISTY pilot trial}

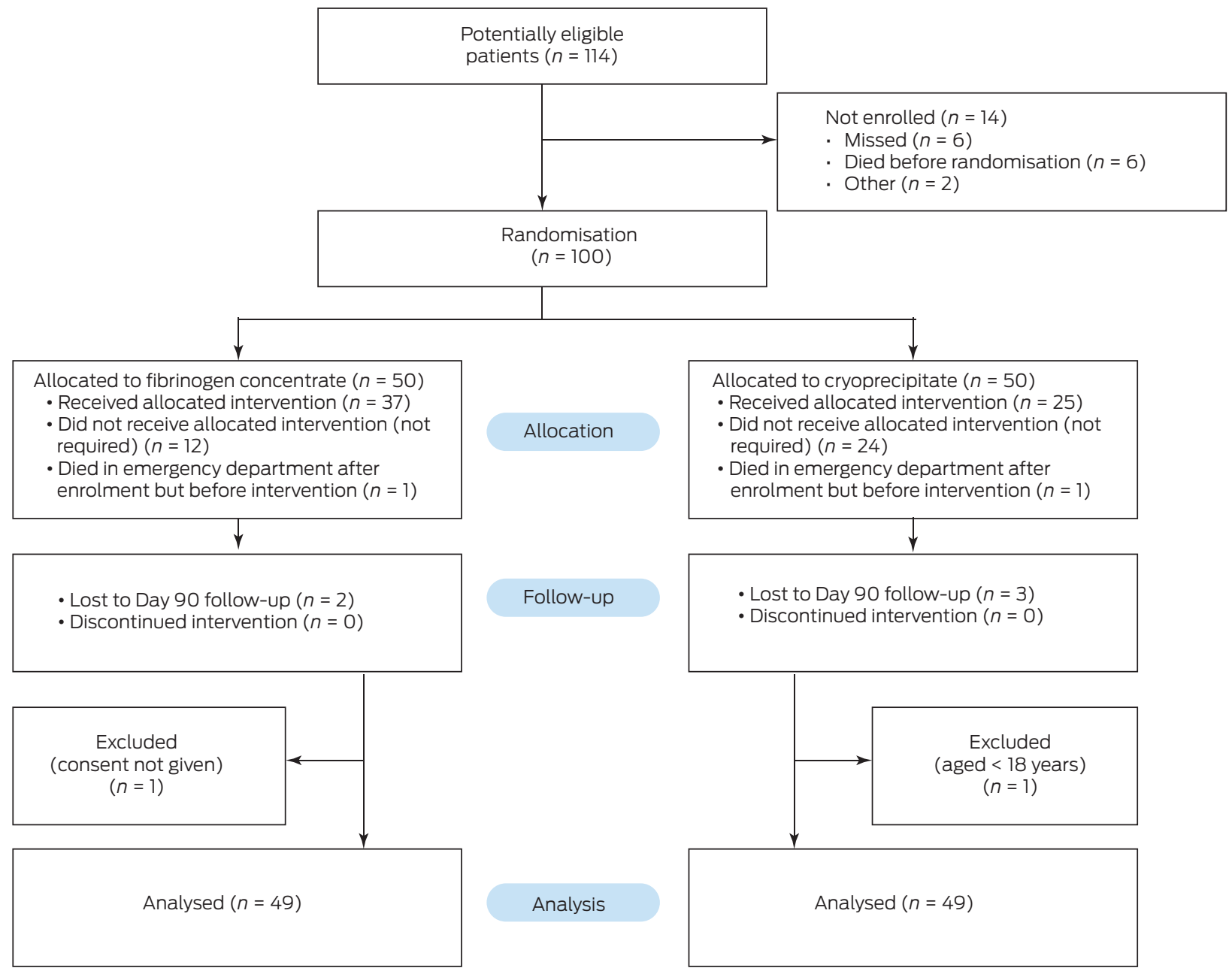

FEISTY = Fibrinogen Early In Severe Trauma studY. 


\section{ORIGINAL ARTICLES}

Table 1. Baseline demographics and physiological characteristics of patients*

\begin{tabular}{|c|c|c|c|c|c|c|}
\hline & \multicolumn{3}{|c|}{ All randomly allocated patients } & \multicolumn{3}{|c|}{$\begin{array}{l}\text { Patients given intervention } \\
\text { (FC or Cryo) }\end{array}$} \\
\hline & $\begin{array}{c}\text { All } \\
(n=98)\end{array}$ & $\begin{array}{l}\text { FC arm } \\
(n=49)\end{array}$ & $\begin{array}{c}\text { Cryo arm } \\
(n=49)\end{array}$ & $\begin{array}{c}\text { All } \\
(n=62)\end{array}$ & $\begin{array}{l}\text { FC arm } \\
(n=37)\end{array}$ & $\begin{array}{c}\text { Cryo arm } \\
(n=25)\end{array}$ \\
\hline Age, years & $46(18)$ & $44(17)$ & $48(20)$ & $43(18)$ & $44(17)$ & $41(20)$ \\
\hline Male & 75 (77\%) & $37(76 \%)$ & $38(78 \%)$ & $51(82 \%)$ & $29(78 \%)$ & $22(88 \%)$ \\
\hline Injury severity score & $26(12)$ & $26(12)$ & $26(13)$ & $27(13)$ & $26(12)$ & $30(15)$ \\
\hline APACHE II score & $18(7)$ & $20(9)$ & $17(8)$ & $20(9)$ & $21(10)$ & $18(9)$ \\
\hline \multicolumn{7}{|l|}{ Mechanism of injury } \\
\hline Blunt & $76(78 \%)$ & $37(76 \%)$ & $39(80 \%)$ & $47(76 \%)$ & $26(70 \%)$ & $21(84 \%)$ \\
\hline Penetrating & $20(20 \%)$ & $11(22 \%)$ & $9(18 \%)$ & $14(23 \%)$ & $10(27 \%)$ & $4(16 \%)$ \\
\hline Pre-hospital lowest GCS score & $6(3-15)$ & $3(3-14)$ & $12(3-15)$ & $3(3-15)$ & $3(3-13)$ & $12(3-15)$ \\
\hline Pre-hospital intubation & $45(46 \%)$ & $28(57 \%)$ & $17(35 \%)$ & $36(58 \%)$ & $25(68 \%)$ & $11(44 \%)$ \\
\hline Pre-hospital highest HR & $121(28)$ & $121(24)$ & $120(31)$ & $126(29)$ & $124(26)$ & $130(33)$ \\
\hline Pre-hospital lowest SBP & $87(24)$ & $83(21)$ & $91(27)$ & $87(23)$ & $81(20)$ & $94(24)$ \\
\hline ED highest HR & $121(27)$ & $122(26)$ & $119(28)$ & $123(28)$ & $123(24)$ & $123(32)$ \\
\hline ED lowest SBP & $85(22)$ & $85(21)$ & $85(23)$ & $85(24)$ & $85(23)$ & $85(26)$ \\
\hline
\end{tabular}

APACHE $=$ Acute Physiology and Chronic Health Evaluation. Cryo $=$ cryoprecipitate. $E D=$ emergency department. $F C=$ fibrinogen concentrate. GCS $=$ Glasgow Coma Scale. $\mathrm{HR}=$ heart rate. SBP = systolic blood pressure. ${ }^{*}$ Data are presented as number (percentage), mean (SD) or median (interquartile range).

and 14 were not enrolled (Figure 2). Of the 100 patients randomly assigned to an intervention arm, it was not possible to obtain consent for one patient and one patient was subsequently found to be $<18$ years old. One additional patient was subsequently found to be $<18$ years old (Day 1 following randomisation) but consent was obtained for this patient and additional ethics approval was granted to include them (16.5 years old). This allowed for 98 patients to be included in final analysis. Two patients died in the emergency department very soon after enrolment and before any intervention was given.

Patients were randomised into the trial based on clinical evidence or suspicion of major active haemorrhage, but only received fibrinogen replacement if deemed hypofibrinogenaemic by a pre-defined FIBTEM A5 value. Of the 98 patients included in the final analysis, 62 patients required fibrinogen replacement at some point during their hospital admission (FC, $n=37$; Cryo, $n=25$ ).

Baseline patient characteristics are shown in Table 1. Patients were significantly injured (mean ISS, 26) and predominantly men with a blunt mechanism of injury. The arms were well matched at baseline in terms of haemodynamic parameters and ISS. However, patients in the FC arm potentially had worse neurological status at baseline (lowest pre-hospital median GCS, $3 \vee 12$ ), and a larger proportion of them required pre-hospital intubation.
Pre-hospital highest GCS was lower in the FC arm (median, $12 \vee 15)$. In addition, the mean abbreviated injury scale (AIS) score for head and neck was worse in the FC arm compared with the Cryo arm (mean, $1.8 \vee 1.4$ ), and a greater proportion of patients in the Cryo arm scored zero for head and neck AIS compared with those in the FC arm (64\% [16/25] v 49\% [18/37]). The arms were well matched in terms of baseline laboratory values (Table 2).

\section{Primary outcome}

Of the 62 patients requiring fibrinogen replacement (FIBTEM A5 $\leq 10 \mathrm{~mm}$ ), primary outcome data were available for 60 patients ( $F C, n=35$; Cryo, $n=25$ ) (Figure 3 ). The median (interquartile range [IQR]) time to commencement of FC administration from the time of blood sampling for FIBTEM analysis was 29 min (23-40 min) compared with $60 \mathrm{~min}(40-80 \mathrm{~min})$ for Cryo administration. There was strong evidence that these times to fibrinogen replacement were different between the two arms (log rank test for equality of time to event, $P=0.0001)$. Within $30 \mathrm{~min}$, over half of FC replacement doses had commenced. In contrast, no replacement had commenced before 30 min with Cryo.

The administration of fibrinogen products was rapid; the median (IQR) duration of FC administration was 4 (2-8) min, compared with 12.5 (8-24) min for Cryo. In the FC arm, the median FIBTEM A5 was $8 \mathrm{~mm}$ (IQR, 7-9 mm) with patients 


\section{ORIGINAL ARTICLES}

Table 2. Laboratory data for patients on admission*

\begin{tabular}{|c|c|c|c|c|c|c|}
\hline & \multicolumn{3}{|c|}{ All randomly allocated patients } & \multicolumn{3}{|c|}{ Patients given intervention (FC or Cryo) } \\
\hline & $\begin{array}{c}\text { All } \\
(n=98)\end{array}$ & $\begin{array}{l}\text { FC arm } \\
(n=49)\end{array}$ & $\begin{array}{c}\text { Cryo arm } \\
(n=49)\end{array}$ & $\begin{array}{c}\text { All } \\
(n=62)\end{array}$ & $\begin{array}{l}\text { FC arm } \\
(n=37)\end{array}$ & $\begin{array}{c}\text { Cryo arm } \\
(n=25)\end{array}$ \\
\hline $\mathrm{pH}$ & $7.27(0.13)$ & $7.24(0.13)$ & $7.31(0.10)$ & $7.24(0.15)$ & $7.21(0.16)$ & $7.28(0.11)$ \\
\hline Base excess, $\mathrm{mmol} / \mathrm{L}$ & $-5.9(5.6)$ & $-7.4(6.6)$ & $-4.6(4.1)$ & $-7.5(6.1)$ & $-8.6(6.6)$ & $-5.6(4.6)$ \\
\hline Lactate, mmol/L & $\begin{array}{c}3.8 \\
(1.9-5.3)\end{array}$ & $\begin{array}{c}3.8 \\
(1.9-5.3)\end{array}$ & $\begin{array}{c}2.7 \\
(2.2-3.8)\end{array}$ & $4.1(2.7)$ & $4.5(3.0)$ & $3.6(2.2)$ \\
\hline Haemoglobin, g/L & $135(22)$ & $131(25)$ & $139(18)$ & $136(24)$ & $132(28)$ & $143(17)$ \\
\hline Platelets, $\times 10^{9} / \mathrm{L}$ & $232(84)$ & $224(86)$ & $240(83)$ & $214(82)$ & $213(82)$ & $215(73)$ \\
\hline International normalised ratio & $1.3(0.61)$ & $1.4(0.83)$ & $1.2(0.22)$ & $1.4(0.73)$ & $1.5(0.94)$ & $1.3(0.25)$ \\
\hline
\end{tabular}

* Data are presented as mean (SD) or median (interquartile range).

receiving a median of $3 \mathrm{~g} F C$ (IQR, 2-4 g). In the Cryo arm, the median FIBTEM A5 was $9 \mathrm{~mm}$ (IQR, 5-10 mm) with patients receiving a median of 8 units of Cryo (IQR, 8-14 units).

\section{Secondary outcomes}

The majority of patients received pre-hospital packed red blood cell transfusion, with a median of 1 unit transfused (Table 3). Overall, $44 \%$ of patients required surgical or interventional radiology procedures for haemorrhage control. Slightly more patients assigned to the FC arm receiving the intervention required a haemorrhage control procedure (49\% v 40\%). The majority of patients received tranexamic acid as part of their initial resuscitation, and this proportion was slightly higher for patients in the FC arm who received the intervention than for patients in the Cryo arm who received the intervention ( $87 \% \vee 72 \%)$. There was no difference in transfusion requirements between the two arms, for the whole cohort or the cohort of patients who received the intervention either in the first $24 \mathrm{~h}$ or for the duration of acute hospital admission.

Across the whole cohort, patients received a median of $3.16 \mathrm{~L}$ of crystalloid fluid resuscitation in the first $24 \mathrm{~h}$ after injury. There was no suggestion that patients assigned to the FC arm received more crystalloid or colloid fluid at any stage of resuscitation up to $24 \mathrm{~h}$ after injury (Table 4).

Fibrinogen levels incremented appropriately after both FC and Cryo administration (Table 5). In a linear model using a generalised estimating equation approach to account for

Figure 3. Time to commencement of first FC or Cryo treatment*

\begin{tabular}{|l|c|c|}
\hline & \multicolumn{1}{|c|}{ Patients receiving intervention } \\
\hline & FC & Cryo \\
\hline Patients with FIBTEM A5 $\leq 10 \mathrm{~mm}$ & $35(71 \%)$ & $25(51 \%)$ \\
\hline Time to FC or Cryo, min & $29(23-40)$ & $60(40-80)$ \\
\hline FIBTEM A5, mm & $8(7-9)$ & $9(5-10)$ \\
\hline First dose of FC, $\mathrm{g}$ & $3(2-4)$ & - \\
\hline First dose of Cryo, units & - & $8(8-14)$ \\
\hline
\end{tabular}

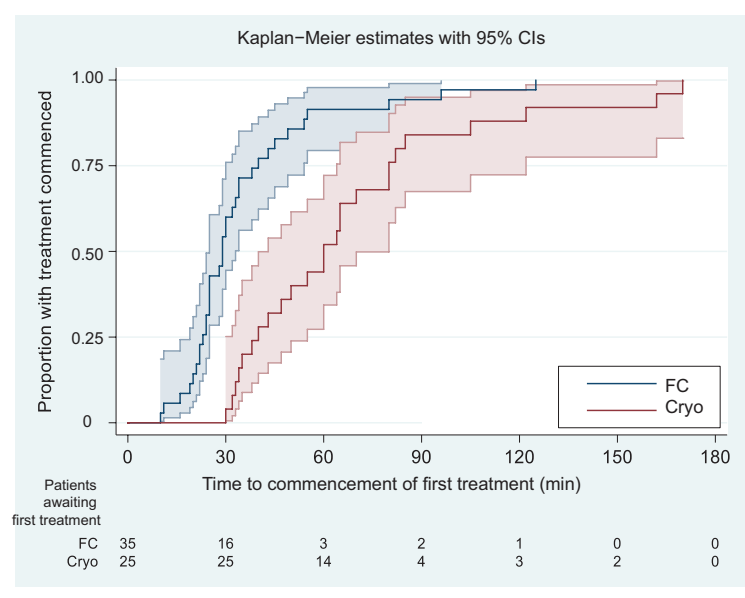

Cryo $=$ cryoprecipitate. $\mathrm{FC}=$ fibrinogen concentrate. FIBTEM A5 = functional fibrinogen assessment at 5 minutes after clot formation. * Data in table are presented as number (percentage) or median (interquartile range). 


\section{ORIGINAL ARTICLES}

Table 3. Transfusion data for patients*

\begin{tabular}{|c|c|c|c|c|c|c|}
\hline & \multicolumn{3}{|c|}{ All randomly allocated patients } & \multicolumn{3}{|c|}{ Patients given intervention (FC or Cryo) } \\
\hline & $\begin{array}{c}\text { All } \\
(n=98)\end{array}$ & $\begin{array}{l}\text { FC arm } \\
(n=49)\end{array}$ & $\begin{array}{c}\text { Cryo arm } \\
(n=49)\end{array}$ & $\begin{array}{c}\text { All } \\
(n=62)\end{array}$ & $\begin{array}{c}\text { FC arm } \\
(n=37)\end{array}$ & $\begin{array}{c}\text { Cryo arm } \\
(n=25)\end{array}$ \\
\hline Surgical or IR procedure ${ }^{\dagger}$ & $43(44 \%)$ & $25(51 \%)$ & $18(37 \%)$ & $28(45 \%)$ & $18(49 \%)$ & $10(40 \%)$ \\
\hline Pre-hospital PRBC & $1(0-2)$ & $1(0-2)$ & $1(0-2)$ & $1(0-2)$ & $1(0-2)$ & $1(0-3)$ \\
\hline Tranexamic acid & $70(71 \%)$ & $38(78 \%)$ & $32(65 \%)$ & $50(80 \%)$ & $32(87 \%)$ & $18(72 \%)$ \\
\hline 24 h PRBC, units & $5(3-8)$ & $5(4-9)$ & $4(2-7)$ & $5.5(3-10)$ & $5(4-10)$ & $6(2-10)$ \\
\hline Total PRBC, units & $6(4-10)$ & $6(5-11)$ & $5(3-8)$ & $7(4-11)$ & $6(4-12)$ & $7(4-11)$ \\
\hline 24 h FFP, units & $0(0-0)$ & $0(0-0)$ & $0(0-0)$ & $0(0-0)$ & $0(0-0)$ & $0(0-4)$ \\
\hline $24 \mathrm{~h}$ platelets, units & $0(0-0)$ & $0(0-0)$ & $0(0-0)$ & $0(0-1)$ & $0(0-1)$ & $0(0-1)$ \\
\hline $24 \mathrm{~h}$ Cryo, units & $0(0-0)$ & $0(0-0)$ & $0(0-16)$ & $0(0-16)$ & $0(0-0)$ & $16(14-24)$ \\
\hline $24 \mathrm{~h} \mathrm{FC,} \mathrm{g}$ & $0(0-3)$ & $0(2-5)$ & $0(0-0)$ & $2(0-4)$ & $3(3-6)$ & $0(0-0)$ \\
\hline
\end{tabular}

$F C=$ fibrinogen concentrate. $C$ ryo $=$ cryoprecipitate. $I R=$ interventional radiology. $P R B C=$ packed red blood cells. FFP $=$ fresh frozen plasma. * Data are presented as number (percentage) or median (interquartile range). † For haemorrhagic control.

Table 4. Volumes of crystalloid and colloid fluid used for resuscitation

\begin{tabular}{|c|c|c|c|c|c|c|}
\hline & \multicolumn{3}{|c|}{ All randomly allocated patients } & \multicolumn{3}{|c|}{ Patients given intervention (FC or Cryo) } \\
\hline & $\begin{array}{c}\text { All } \\
(n=98)\end{array}$ & $\begin{array}{l}\text { FC arm } \\
(n=49)\end{array}$ & $\begin{array}{l}\text { Cryo arm } \\
(n=49)\end{array}$ & $\begin{array}{c}\text { All } \\
(n=62)\end{array}$ & $\begin{array}{l}\text { FC arm } \\
(n=37)\end{array}$ & $\begin{array}{l}\text { Cryo arm } \\
(n=25)\end{array}$ \\
\hline $\begin{array}{l}\text { Pre-hospital } \\
\text { crystalloid, L }\end{array}$ & $\begin{array}{c}0.50 \\
(0.30-1.25)\end{array}$ & $\begin{array}{c}0.50 \\
(0.35-1.25)\end{array}$ & $\begin{array}{c}0.50 \\
(0.20-1.30)\end{array}$ & $\begin{array}{c}0.50 \\
(0.25-1.50)\end{array}$ & $\begin{array}{c}0.50 \\
(0.32-1.37)\end{array}$ & $\begin{array}{c}0.50 \\
(0.20-1.50)\end{array}$ \\
\hline $\begin{array}{l}\text { Emergency } \\
\text { department } \\
\text { crystalloid, L }\end{array}$ & $\begin{array}{c}1.00 \\
(0.5-1.17)\end{array}$ & $\begin{array}{c}1.00 \\
(0.5-1)\end{array}$ & $\begin{array}{c}1.00 \\
(0.62-1.75)\end{array}$ & $\begin{array}{c}1.00 \\
(0.50-1.10)\end{array}$ & $\begin{array}{c}1.00 \\
(0.50-1.00)\end{array}$ & $\begin{array}{c}1.00 \\
(0.75-2.00)\end{array}$ \\
\hline $\begin{array}{l}\text { Operating theatre } \\
\text { colloid, L }\end{array}$ & $\begin{array}{c}0.50 \\
(0.39-1.50)\end{array}$ & $\begin{array}{c}1.00 \\
(0.50-0.18)\end{array}$ & $\begin{array}{c}0.50 \\
(0.18-1.00)\end{array}$ & $\begin{array}{c}0.50 \\
(0.19-1.00)\end{array}$ & $\begin{array}{c}1.00 \\
(0.25-2.10)\end{array}$ & $\begin{array}{c}0.50 \\
(0.18-0.50)\end{array}$ \\
\hline $\begin{array}{l}\text { Operating theatre } \\
\text { crystalloid, L }\end{array}$ & $\begin{array}{c}2.00 \\
(1.10-2.30)\end{array}$ & $\begin{array}{c}2.00 \\
(1.25-2.16)\end{array}$ & $\begin{array}{c}2.00 \\
(1.00-2.32)\end{array}$ & $\begin{array}{c}2.00 \\
(1.1-2.8)\end{array}$ & $\begin{array}{c}2.00 \\
(1.5-2.8)\end{array}$ & $\begin{array}{c}1.53 \\
(0.75-3.86)\end{array}$ \\
\hline 24 h colloid, $\mathrm{L}$ & $\begin{array}{c}0 \\
(0-0.50)\end{array}$ & $\begin{array}{c}0 \\
(0-1.00)\end{array}$ & $\begin{array}{c}0 \\
(0-0.25)\end{array}$ & $\begin{array}{c}0 \\
(0-1.00)\end{array}$ & $\begin{array}{c}0 \\
(0-1.00)\end{array}$ & $\begin{array}{c}0 \\
(0-0.50)\end{array}$ \\
\hline 24 h crystalloid, L & $\begin{array}{c}3.16 \\
(1.80-4.93)\end{array}$ & $\begin{array}{c}3.22 \\
(2.00-4.87)\end{array}$ & $\begin{array}{c}3.10 \\
(1.68-4.93)\end{array}$ & $\begin{array}{c}3.63 \\
(2.00-5.68)\end{array}$ & $\begin{array}{c}3.50 \\
(1.80-5.27)\end{array}$ & $\begin{array}{c}4.08 \\
(2.31-6.40)\end{array}$ \\
\hline
\end{tabular}

Cryo $=$ cryoprecipitate. $\mathrm{FC}=$ fibrinogen concentrate. ${ }^{*}$ Data are presented as median (interquartile range), rounded to nearest $10 \mathrm{~mL}$.

clustering of pre-treatment and post-treatment results within individual patients (and also using robust error calculations), strong evidence was found of a greater FIBTEM A5 in the first test after Cryo compared with before treatment (mean difference, $2.4 \mathrm{~mm} ; 95 \% \mathrm{Cl}, 1.1-3.7 \mathrm{~mm} ; P<0.0005)$. There was also strong evidence that $\mathrm{FC}$ treatment was associated with an elevation of FIBTEM A5 amplitude above the value seen with Cryo (mean difference, $2.6 \mathrm{~mm} ; 95 \% \mathrm{Cl}, 1.1-4.1 \mathrm{~mm}$; $P=0.001$ ) (Table 5). There was strong evidence of increased FibC level after treatment compared with before treatment with Cryo (mean difference, $0.78 \mathrm{~g} / \mathrm{L} ; 95 \% \mathrm{Cl}, 0.34-1.2 ; P<0.0005$ ). An increase was also observed after FC treatment, but this was not markedly different to that after Cryo treatment.
Considering the whole analysed cohort, the overall trajectories of FIBTEM A5 and FibC levels are shown in Figure 4. This shows substantial and progressive increments in FIBTEM $A 5$ and FibC. There was no suggestion of higher FIBTEM A5 or FibC levels in patients who received an intervention (FC or Cryo) compared with those who did not, although there were more FIBTEM $A 5$ results available than FibC results.

All-cause mortality at 90 days for the whole cohort was $15.3 \%(n=15)$ (Table 6$)$. There were more deaths among those allocated to the FC $\operatorname{arm}(24 \%, n=12)$ compared with those allocated to the Cryo arm $(6 \%, n=3)$. All deaths occurred within 96 hours of injury. About half of the deaths 
Table 5. FIBTEM A5 and FibC before and after first treatment with FC or Cryo*

FIBTEM A5 $(\mathrm{mm})$

\begin{tabular}{cccccc}
\cline { 2 - 3 } \cline { 5 - 6 } & Before treatment & After treatment & & Before treatment & After treatment \\
\cline { 2 - 3 } FC arm & $7.5(2.1)$ & $12.8(3.4)$ & & $1.7(0.50)$ & $2.3(0.56)$ \\
Cryo arm & $7.7(2.4)$ & $10.2(2.6)$ & & $1.7(0.53)$ & $2.5(0.90)$ \\
\hline
\end{tabular}

$\mathrm{FC}=$ fibrinogen concentrate. $\mathrm{Cryo}=$ cryoprecipitate. $\mathrm{FibC}=$ Clauss fibrinogen. ${ }^{*}$ Data are presented as mean (SD).

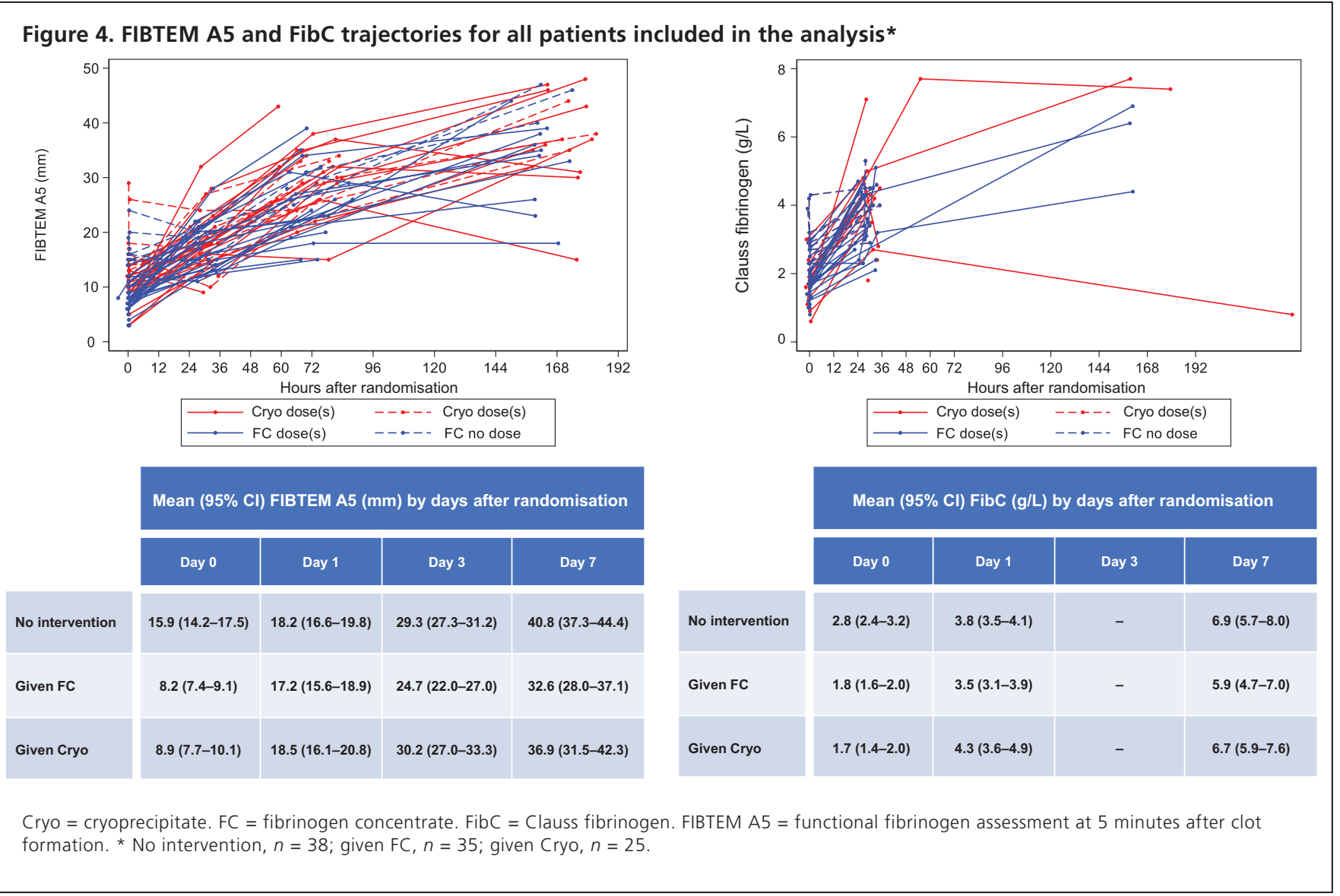

were due to head injury - six in the FC arm and one in the Cryo arm. All patients who died had a pre-hospital GCS of 3. Three patients who subsequently died had a pre-hospital cardiac arrest with return of spontaneous circulation before arrival at hospital. Two patients died of exsanguination. Two patients in the FC arm died of multiple organ failure. Twenty patients experienced a thromboembolic event (the majority of these events being venous thromboembolism) but there was no suggestion of a large difference between the two arms. Consistent with the imbalance in mortality, the FC arm had shorter median intensive care unit length of stay, median duration of mechanical ventilation and median hospital length of stay.

\section{Discussion}

To our knowledge, this is the first randomised controlled trial comparing FC transfusion with Cryo transfusion in severely injured trauma patients. Our results show that in severely injured hypofibrinogenaemic trauma patients, transfusion of FC may be achieved substantially faster than transfusion of Cryo, by a margin of about 30 minutes. There is increasing recognition and substantial evidence to support the importance of fibrinogen in effective clot formation in traumatic haemorrhage. ${ }^{12,15}$ However, the optimal timing, method and dosing of fibrinogen replacement remain under debate. ${ }^{28,46}$ 
Table 6. Occupancy data and clinical events that occurred during the study period

\begin{tabular}{|c|c|c|c|}
\hline & Given FC $(n=37)$ & Given Cryo $(n=25)$ & No intervention $(n=38)$ \\
\hline Intensive care unit length of stay, days & $3.7(1.8-14)$ & $7.7(2.7-16)$ & $2.9(1.6-9.3)$ \\
\hline Duration of mechanical ventilation, $\mathrm{h}$ & $57(17-305)$ & $111(0-344)$ & $35(12-162)$ \\
\hline Hospital length of stay, days & $12(3.8-37)$ & $22(13-41)$ & $14(9.5-25)$ \\
\hline Arterial thrombosis & 1 & 1 & 1 \\
\hline Myocardial infarct & 0 & 0 & 1 \\
\hline Cerebrovascular accident & 1 & 1 & 0 \\
\hline Venous thrombosis & 6 & 7 & 4 \\
\hline Deep vein thrombosis & 4 & 5 & 3 \\
\hline Pulmonary embolism & 2 & 2 & 1 \\
\hline Sepsis & 14 & 11 & 16 \\
\hline Death & 11 & 2 & 2 \\
\hline Traumatic brain injury & 6 & 1 & 0 \\
\hline Multiple organ failure & 2 & 0 & 0 \\
\hline Exsanguination & 1 & 1 & 0 \\
\hline Cardiac arrest in emergency department & 2 & 0 & 2 \\
\hline
\end{tabular}

* Data are presented as median (interquartile range) or absolute value.

Early transfusion of high fixed-ratio blood products as part of a major haemorrhage protocol (MHP) in traumatic haemorrhage is beneficial for achieving haemostasis and reducing early death from exsanguination. ${ }^{36}$ However, early and empiric delivery of specific fibrinogen-containing products is not standard in most fixed ratio MHPs. Several studies have reported that fixed ratio MHPs are ineffective in maintaining adequate fibrinogen levels. ${ }^{23,47}$ Cryo is commonly used in MHPs to replace fibrinogen, but there can be significant delays to Cryo transfusion and a large proportion of patients do not receive Cryo as part of a fixed ratio MHP. ${ }^{17,48,49}$ This has led to several trials evaluating the feasibility of early replacement of fibrinogen using different products. ${ }^{29,31,32}$

CRYOSTAT 1 reported that it is feasible to use Cryo empirically as part of a fixed ratio $\mathrm{MHP}$, with a median time to administration of 60 minutes. ${ }^{29}$ One potential advantage of FC is the rapid time to delivery, as it can be stored in the trauma bay, and rapidly reconstituted and administered.50 In our institution, we recently reported median times to administration of 22 minutes for FC and 61 minutes for Cryo. ${ }^{40,41}$ The FiiRST trial reported that early FC administration was feasible (96\% of patients received the intervention within 1 hour) and increased plasma fibrinogen levels during traumatic haemorrhage. ${ }^{31}$ In contrast, the E-FIT 1 trial reported that administration of FC within 45 minutes of hospital admission was not feasible. 32 In our trial, we showed that early administration of FC is feasible and can be achieved significantly faster than administration of Cryo. We also showed that Cryo can be administered quicker than previously reported and in a time frame consistent with CRYOSTAT 1.29 The faster administration times for FC in our trial compared with FiiRST and E-FIT 1 are probably because FiiRST and E-FIT 1 were blinded placebo-controlled trials with longer times to reconstitution of FC, whereas our trial was not blinded and was designed to replicate real-life trauma resuscitation.

Another major difference in our trial compared with previous trials investigating fibrinogen replacement is that randomly assigned patients only received the intervention if hypofibrinogenaemia (FIBTEM A5 $\leq 10 \mathrm{~mm}$ ) was evident and a fixed dose was not used. Of the 100 patients assigned on clinical suspicion of major haemorrhage, $65 \%$ were hypofibrinogenaemic, which is consistent with other trials where a substantial proportion of patients were not hypofibrinogenaemic at randomisation but received empiric fixed dose interventio. ${ }^{31,32}$ Our trial used the FIBTEM assay to identify patients with hypofibrinogenaemia and subsequently guide fibrinogen dosing. Growing evidence supports the use of viscoelastic haemostatic assays (VHAs) to rapidly guide targeted factor replacement in traumatic haemorrhage, but comparative data from randomised controlled trials are limited.51,52 A recent single-centre randomised controlled trial reported significant reductions in blood product transfusion and improved survival with a VHA-guided MHP. ${ }^{53}$ The results of the recently 


\section{ORIGINAL ARTICLES}

completed ITACTIC (Implementing Treatment Algorithms for the Correction of Trauma-Induced Coagulopathy) trial, comparing efficacy of VHA and standard coagulation tests in traumatic haemorrhage, are eagerly awaited. ${ }^{54}$ While evidence of a positive impact on mortality is currently equivocal, it is clear that VHAs can be used to rapidly and reliably identify coagulopathic trauma patients. ${ }^{55-57}$ The FIBTEM assay (using clot amplitude at 5 minutes) can be used as a marker of TIC and used to predict risk of massive transfusion, and it correlates well with standard laboratory measures of fibrinogen concentration. ${ }^{14,57,58}$ The fibrinogen replacement threshold used in our trial is supported by data from the TACTIC investigators. ${ }^{37}$ Use of FIBTEM A5 did not delay administration of either product in our trial as the time to administration of FC or Cryo was from time of blood draw for the assay, not from time of FIBTEM A5 result.

The dosing of FC and Cryo in our trial was guided by the degree of hypofibrinogenaemia. This is in contrast to previously published trials, where an empiric fixed dose of FC or Cryo was administered. In our trial, patients received a median of 3 grams of FC or a median of 8 units of Cryo, which resulted in significant increments in fibrinogen levels. The quantities of FC and Cryo required in our trial to maintain acceptable fibrinogen levels were less than those used in trials employing an empiric fixed-dose strategy. ${ }^{29,32}$ Indeed, the authors of FiiRST suggest that the empiric administration of 6 grams of FC may have been too much, and that lower doses could be considered in future trials. ${ }^{31}$ Several trials investigating empiric FC use in non-traumatic haemorrhage have failed to demonstrate a benefit for FC. 59,60 This suggests that it is difficult to predict which patients will benefit from fibrinogen replacement based on clinical features alone, and there is likely no benefit in treating those who are not hypofibrinogenaemic. It seems logical to treat patients in whom hypofibrinogenaemia is contributing to ongoing haemorrhage and base fibrinogen replacement dosing on degree of hypofibrinogenaemia.

Blood product transfusion requirements were not different between the two arms of our trial, both at 24 hours or for the duration of hospital admission. More patients in the FC arm required surgical or interventional radiology procedures for haemorrhage control. Only two patients died of uncontrolled haemorrhage. There was no difference in the volume of crystalloid or colloid transfused between the arms, with patients receiving a median of 3.16 litres of crystalloid transfusion in the first 24 hours after injury. This is important, as there are concerns that a VHA-guided protocol using factor concentrates may result in additional non-blood product fluid resuscitation, which can be detrimental.

Even though patients in our trial were severely injured (mean ISS, 26), the mortality rate (15.3\%) was less than that generally reported in trauma research publications. ${ }^{4}$ While our study was a small pilot trial that was not powered for mortality, it had more deaths in the FC arm (12 v 3), although only two deaths were attributed to exsanguination. All deaths occurred within 96 hours of injury and a substantial proportion were due to traumatic brain injury. The higher death rate in the FC arm could be explained by an imbalance in the degree of traumatic brain injury between the two arms. The median pre-hospital lowest GCS in the FC arm was 3, compared with 12 in the Cryo arm, and a greater proportion of patients in the FC arm required pre-hospital intubation (68\% $\vee 44 \%)$. There was no safety signal for excess venous thromboembolic complications for FC compared with Cryo. This is consistent with data suggesting that no increased risk of thromboembolic complications is associated with FC or Cryo transfusion. 29,32,61-64

Fibrinogen levels measured by FIBTEM A5 and FibC incremented in both arms after the intervention to levels widely accepted to be adequate for clot formation (FIBTEM A5 > $10 \mathrm{~mm}$ and FibC > $2 \mathrm{~g} / \mathrm{L}$ ). There was no suggestion in either arm that plasma fibrinogen levels after injury exceeded what would be expected subsequent to severe trauma. ${ }^{29,65}$ In addition, patients who received FC or Cryo did not have higher fibrinogen levels than those who were assigned to an intervention but did not receive one.

This Australian multicentre trauma transfusion trial shows that important research on severely injured multitrauma patients can be performed in the demanding setting of trauma resuscitation. Recruitment into the trial was completed in 10 months and made possible by the research infrastructure and dedication of the project coordination team, as $62 \%$ of patients were recruited outside of standard working hours. The research infrastructure and knowledge that we gained from the FEISTY pilot trial formed the basis for a currently recruiting study on fibrinogen use in severe paediatric trauma — FEISTY Junior (NCT03508141).

Our trial has several limitations. Although it was larger than the two previous trials of FC use in trauma (FiiRST and E-FIT 1) combined, it was a small pilot feasibility trial. It was designed to evaluate the difference in time to administer fibrinogen replacement in severely injured trauma patients. It was not powered to evaluate clinical outcomes and, as such, the secondary outcome measures should be interpreted with caution. ${ }^{66}$ Despite randomisation, the small sample size meant that there were baseline imbalances between the two arms, including severity of traumatic brain injury, which was most likely a chance occurrence.

The observational evidence base that supports early fibrinogen replacement in severe trauma is expanding. ${ }^{19,63,67,68}$ Recently published reviews describe limited evidence comparing FC with Cryo and conclude that it is not possible to recommend one product over the other. ${ }^{46,69}$ CRYOSTAT-2 is currently recruiting in all major trauma centres in the United Kingdom and will investigate 


\section{ORIGINAL ARTICLES}

the effects of early empiric delivery of Cryo as part of an MHP. So far it has recruited over 1000 patients, making it one of the largest trials to date in trauma patients with major haemorrhage.

It is imperative that robust and clinically relevant trials are performed to investigate fibrinogen replacement strategies in severe trauma before widespread practice changes are implemented without a firm evidence base. ${ }^{70,71}$ The increasing trend towards the use of FC for fibrinogen replacement is not supported by a sound evidence base. ${ }^{28,72}$ The potential benefits related to the rapid administration of FC may be outweighed by the additional coagulation factors present in Cryo. A large multicentre randomised controlled trial comparing FC to Cryo - in terms of efficacy, safety and economic implications - is urgently needed. The trial should have patient-centred clinical outcomes, target a specific group of severely injured trauma patients who have major haemorrhage and evidence of hypofibrinogenaemia, and account for severity of traumatic brain injury.

\section{Conclusion}

The FEISTY pilot trial showed that fibrinogen replacement may be achieved more rapidly with FC compared with Cryo in adult trauma patients. It also showed that it is feasible to rapidly administer a guided dose of FC or Cryo to hypofibrinogenaemic patients in the complex setting of multitrauma resuscitation. Data from this trial will inform the design of a larger trial comparing FC to Cryo in severely injured trauma patients.

Acknowledgements: We acknowledge all members of the FEISTY trial investigators group and staff at participating sites whose hard work and dedication was instrumental in bringing this project to fruition. Gold Coast University Hospital: Sarah Czuchwicki, Kerin Walters, Jody Paxton, Mandy Tallott, Anthony Ghent, Fiona Clark, Renee Nelson, Kate Dale. Gold Coast University Hospital Trauma Service, Sunnelle Englebrecht, Quirine O'Loughlin, Haley Oberhardt and Andrew Donohue. Princess Alexandra Hospital: Rob Eley, Clinton Patricks, Jason Meyer, Chantelle Judge, Deborah Cooper, Robert Bird. Royal Brisbane and Women's Hospital: Jeremy Cohen, Sue Williams, Sue Freeney, Kevin Chu, Tegwen Howell, Nathan Brown. Royal Brisbane and Women's Hospital Trauma Service, Marc Maguire, John Rowell. Townsville Hospital and Health Service: Kiran Somani, Luke Burman, Leonie Jones, Susan Montgomery, John Casey, Michael Wilhelm, Andrew Cross, Amanda Krauklis, Michael Corkeron, Ailee Ross and Jeremy Furyk. Australian Red Cross Lifeblood: Phillip Mondy. Australian governments fund Australian Red Cross Lifeblood to provide blood, blood products and services to the Australian community.

The program of trauma research that we undertake is supported by grants from the Emergency Medicine Foundation (grant
EMPJ357R25-2016), National Blood Authority (grant 127) and Gold Coast University Hospital (grant 150-16.6.16). This trial was supported by Werfen, Haemonetics and CSL Behring in terms of materials only. There was no industry input into trial design, data collection, data analysis or dissemination of results. Funding was managed by the coordinating site - Gold Coast University Hospital and University of Queensland.

Competing interests: James Winearls has received educational, travel and research support from Werfen, Haemonetics and CSL Behring. Shane George has received research support for FEISTY Junior from Werfen, Haemonetics and CSL Behring.

\section{Author details}

James Winearls $1,2,3,4$

Martin Wullschleger ${ }^{5}$

Elizabeth Wake ${ }^{5}$

Zoe McQuilten ${ }^{6,7}$

Michael Reade $8,9,10$

Catherine Hurn 2,10

Glenn Ryan 2,11

Melita Trout ${ }^{12,13}$

James Walsham 2,11

Anthony Holley 2,10

Shane George 2,14,15

Wayne Dyer ${ }^{16}$

James McCullough ${ }^{1}$

Gerben Keijzers 1,3,17

John Fraser2,18

Jeffrey Presneill19,20

Don Campbell ${ }^{5}$

1 Intensive Care Unit, Gold Coast University Hospital, Gold Coast, QLD, Australia.

2 School of Medicine, University of Queensland, Brisbane, QLD, Australia.

3 School of Medical Sciences, Griffith University, Gold Coast, QLD, Australia.

4 St Andrews War Memorial Hospital Brisbane, QLD, Australia.

5 Trauma Service, Gold Coast University Hospital, Gold Coast, QLD, Australia.

6 Transfusion Research Unit, Monash University, Melbourne, VIC, Australia.

7 Monash Health, Melbourne, VIC, Australia.

8 Military Medicine and Surgery, Joint Health Command, Australian Defence Force.

9 Faculty of Medicine, University of Queensland, Brisbane, QLD, Australia.

10 Royal Brisbane and Women's Hospital, Brisbane, QLD, Australia.

11 Princess Alexandra Hospital, Brisbane, QLD, Australia.

12 Townsville Hospital, Townsville, QLD, Australia. 


\section{ORIGINAL ARTICLES}

13 Faculty of Medicine, James Cook University, Townsville, QLD, Australia.

14 Emergency Department and Children's Critical Care Service, Gold Coast University Hospital, Gold Coast, QLD, Australia.

15 Paediatric Critical Care Research Group, Child Health Research Centre, University of Queensland, Brisbane, QLD, Australia.

16 Australian Red Cross Lifeblood.

17 Faculty of Health Sciences and Medicine, Bond University,

Gold Coast, QLD, Australia.

18 Critical Care Research Group, Prince Charles Hospital,

Brisbane, QLD, Australia.

19 Intensive Care Unit, Royal Melbourne Hospital, Melbourne,

VIC, Australia.

20 University of Melbourne, Melbourne, VIC, Australia.

Correspondence: james.winearls@health.qld.gov.au

\section{References}

1 Cothren CC, Moore EE, Hedegaard HB, Meng K. Epidemiology of urban trauma deaths: a comprehensive reassessment 10 years later. World J Surg 2007; 31: 1507-11.

2 Kauvar DS, Wade CE. The epidemiology and modern management of traumatic hemorrhage: US and international perspectives. Crit Care 2005; 9 Suppl 5: S1-9.

3 Norton R, Kobusingye O. Injuries. N Engl J Med 2013; 368: 1723-30.

4 Cole E, Weaver A, Gall L, et al. A decade of damage control resuscitation: new transfusion practice, new survivors, new directions. Ann Surg 2019; doi: 10.1097/ sla.0000000000003657 [Epub ahead of print].

5 Brohi K, Cohen MJ, Davenport RA. Acute coagulopathy of trauma: mechanism, identification and effect. Curr Opin Crit Care 2007; 13: 680-5.

6 Dobson GP, Letson HL, Sharma R, et al. Mechanisms of early trauma-induced coagulopathy: the clot thickens or not? J Trauma Acute Care Surg 2015; 79: 301-9.

7 Duque P, Mora L, Levy JH, Schöchl H. Pathophysiological response to trauma-induced coagulopathy: a comprehensive review. Anesth Analg 2020; 130: 654-64.

8 Hoffman M, Monroe DM 3rd. A cell-based model of hemostasis. Thromb Haemost 2001; 85: 958-65.

9 Levy JH, Welsby I, Goodnough LT. Fibrinogen as a therapeutic target for bleeding: a review of critical levels and replacement therapy. Transfusion 2014; 54: 1389-405; quiz 1388.

10 Lang $\mathrm{T}$, Johanning $\mathrm{K}$, Metzler $\mathrm{H}$, et al. The effects of fibrinogen levels on thromboelastometric variables in the presence of thrombocytopenia. Anesth Analg 2009; 108: 751-8.

11 Mosesson MW. Fibrinogen and fibrin structure and functions. J Thromb Haemost 2005; 3: 1894-904.

12 Hagemo JS, Stanworth S, Juffermans NP, et al. Prevalence, predictors and outcome of hypofibrinogenaemia in trauma: a multicentre observational study. Crit Care 2014; 18: R52.
13 Floccard B, Rugeri L, Faure A, et al. Early coagulopathy in trauma patients: an on-scene and hospital admission study. Injury 2012; 43: 26-32.

14 Schochl H, Cotton B, Inaba K, et al. FIBTEM provides early prediction of massive transfusion in trauma. Crit Care 2011; 15: R265.

15 Inaba K, Karamanos E, Lustenberger T, et al. Impact of fibrinogen levels on outcomes after acute injury in patients requiring a massive transfusion. J Am Coll Surg 2013; 216: 290-7.

16 Rourke C, Curry N, Khan S, et al. Fibrinogen levels during trauma hemorrhage, response to replacement therapy, and association with patient outcomes. J Thromb Haemost 2012; 10: 1342-51.

17 McQuilten ZK, Bailey M, Cameron PA, et al. Fibrinogen concentration and use of fibrinogen supplementation with cryoprecipitate in patients with critical bleeding receiving massive transfusion: a bi-national cohort study. $\mathrm{Br} \mathrm{J}$ Haematol 2017; 179: 131-41.

18 McQuilten ZK, Wood EM, Bailey M, et al. Fibrinogen is an independent predictor of mortality in major trauma patients: a five-year statewide cohort study. Injury 2017; 48: 107481.

19 Innerhofer $\mathrm{P}$, Westermann I, Tauber $\mathrm{H}$, et al. The exclusive use of coagulation factor concentrates enables reversal of coagulopathy and decreases transfusion rates in patients with major blunt trauma. Injury 2013; 44: 209-16.

20 Morrison JJ, Ross JD, Dubose JJ, et al. Association of cryoprecipitate and tranexamic acid with improved survival following wartime injury: findings from the MATTERs II study. JAMA Surg 2013; 148: 218-25.

21 Spahn DR, Bouillon B, Cerny V, et al. The European guideline on management of major bleeding and coagulopathy following trauma: fifth edition. Crit Care 2019; 23: 98.

22 Chowdary $P$, Saayman AG, Paulus $U$, et al. Efficacy of standard dose and $30 \mathrm{ml} / \mathrm{kg}$ fresh frozen plasma in correcting laboratory parameters of haemostasis in critically ill patients. Br J Haematol 2004; 125: 69-73.

23 Khan S, Davenport R, Raza I, et al. Damage control resuscitation using blood component therapy in standard doses has a limited effect on coagulopathy during trauma hemorrhage. Intensive Care Med 2015; 41: 239-47.

24 Kozek-Langenecker S, Sorensen B, Hess JR, Spahn DR. Clinical effectiveness of fresh frozen plasma compared with fibrinogen concentrate: a systematic review. Crit Care 2011; 15: R239.

25 Innerhofer P, Fries D, Mittermayr M, et al. Reversal of trauma-induced coagulopathy using first-line coagulation factor concentrates or fresh frozen plasma (RETIC): a singlecentre, parallel-group, open-label, randomised trial. Lancet Haematol 2017; 4: e258-71.

26 Ranucci M, Solomon C. Supplementation of fibrinogen in acquired bleeding disorders: experience, evidence, guidelines, and licences. Br J Anaesth 2012; 109: 135-7.

27 Nascimento B, Goodnough LT, Levy JH. Cryoprecipitate 


\section{ORIGINAL ARTICLES}

therapy. Br J Anaesth 2014; 113: 922-34.

28 Novak A, Stanworth SJ, Curry N. Do we still need cryoprecipitate? Cryoprecipitate and fibrinogen concentrate as treatments for major hemorrhage - how do they compare? Expert Rev Hematol 2018; 11: 351-60.

29 Curry N, Rourke C, Davenport R, et al. Early cryoprecipitate for major haemorrhage in trauma: a randomised controlled feasibility trial. Br J Anaesth 2015; 115: 76-83.

30 Wikkelso $A$, Lunde J, Johansen $M$, et al. Fibrinogen concentrate in bleeding patients. Cochrane Database Syst Rev 2013; (8): CD008864.

31 Nascimento $B$, Callum J, Tien $H$, et al. Fibrinogen in the initial resuscitation of severe trauma (FiiRST): a randomized feasibility trial. Br J Anaesth 2016; 117: 775-82.

32 Curry $\mathrm{N}$, Foley $\mathrm{C}$, Wong $\mathrm{H}$, et al. Early fibrinogen concentrate therapy for major haemorrhage in trauma (E-FIT 1): results from a UK multi-centre, randomised, double blind, placebocontrolled pilot trial. Crit Care 2018; 22: 164.

33 Okerberg CK, Williams LA 3rd, Kilgore ML, et al. Cryoprecipitate AHF vs. fibrinogen concentrates for fibrinogen replacement in acquired bleeding patients - an economic evaluation. Vox Sang 2016; 111: 292-8.

34 Winearls J, Wullschleger M, Wake E, et al. Fibrinogen Early In Severe Trauma studY (FEISTY): study protocol for a randomised controlled trial. Trials 2017; 18: 241.

35 Cotton BA, Dossett LA, Haut ER, et al. Multicenter validation of a simplified score to predict massive transfusion in trauma. J Trauma 2010; 69 Suppl 1: S33-9.

36 Holcomb JB, Tilley BC, Baraniuk S, et al. Transfusion of plasma, platelets, and red blood cells in a 1: 1: 1 vs a 1 : 1: 2 ratio and mortality in patients with severe trauma: the PROPPR randomized clinical trial. JAMA 2015; 313: 471-82.

37 Baksaas-Aasen K, Van Dieren S, Balvers K, et al. Datadriven development of ROTEM and TEG algorithms for the management of trauma hemorrhage: a prospective observational multicenter study. Ann Surg 2019; 270: 117885.

38 Winearls J, Reade M, Miles $\mathrm{H}$, et al. Targeted coagulation management in severe trauma: the controversies and the evidence. Anesth Analg 2016; 123: 910-24.

39 Juffermans NP, Wirtz MR, Balvers K, et al. Towards patientspecific management of trauma hemorrhage: the effect of resuscitation therapy on parameters of thromboelastometry. J Thromb Haemost 2019; 17: 441-8.

40 Ho D, Chan E, Campbell D, et al. Targeted cryoprecipitate transfusion in severe traumatic haemorrhage. Injury 2020; 51: 1949-55.

41 Seebold JA, Campbell D, Wake E, et al. Targeted fibrinogen concentrate use in severe traumatic haemorrhage. Crit Care Resusc 2019; 21: 171-8.

42 Solomon C, Pichlmaier $U$, Schoechl H, et al. Recovery of fibrinogen after administration of fibrinogen concentrate to patients with severe bleeding after cardiopulmonary bypass surgery. Br J Anaesth 2010; 104: 555-62.

43 Danes AF, Cuenca LG, Bueno SR, et al. Efficacy and tolerability of human fibrinogen concentrate administration to patients with acquired fibrinogen deficiency and active or in highrisk severe bleeding. Vox Sang 2008; 94: 221-6.

$44 \mathrm{ICH}$ Expert Working Group. ICH harmonised guideline: addendum on estimands and sensitivity analysis in clinical trials to the guideline on statistical principles for clinical trials E9(R1). https://database.ich.org/sites/default/files/E9R1_Step4_Guideline_2019_1203.pdf (viewed May 2020).

45 Hanley JA, Negassa A, Edwardes MD, Forrester JE. Statistical analysis of correlated data using generalized estimating equations: an orientation. Am J Epidemiol 2003; 157: 36475.

46 Wong H, Curry N. Do we need cryoprecipitate in the era of fibrinogen concentrate and other specific factor replacement options? ISBT Sci Ser 2018; 13: 23-8.

47 Chambers LA, Chow SJ, Shaffer LE. Frequency and characteristics of coagulopathy in trauma patients treated with a low- or high-plasma-content massive transfusion protocol. Am J Clin Pathol 2011; 136: 364-70.

48 Holcomb JB, Fox EE, Zhang $X$, et al. Cryoprecipitate use in the PROMMTT study. J Trauma Acute Care Surg 2013; 75 (1 Suppl 1): S31-9.

49 Stanworth SJ, Davenport R, Curry N, et al. Mortality from trauma haemorrhage and opportunities for improvement in transfusion practice. Br J Surg 2016; 103: 357-65.

50 Karri JV, Cardenas JC, Johansson PI, et al. In vitro efficacy of RiaSTAP after rapid reconstitution. J Surg Res 2014; 190: 655-61.

51 Da Luz LT, Nascimento B, Shankarakutty AK, et al. Effect of thromboelastography $(\mathrm{TEG}(\mathrm{R}))$ and rotational thromboelastometry $(\operatorname{ROTEM}(\mathrm{R}))$ on diagnosis of coagulopathy, transfusion guidance and mortality in trauma: descriptive systematic review. Crit Care 2014; 18: 518.

52 Hunt H, Stanworth S, Curry N, et al. Thromboelastography (TEG) and rotational thromboelastometry (ROTEM) for trauma induced coagulopathy in adult trauma patients with bleeding. Cochrane Database Syst Rev 2015; (2): CD010438.

53 Gonzalez E, Moore EE, Moore HB, et al. Goal-directed hemostatic resuscitation of trauma-induced coagulopathy: a pragmatic randomized clinical trial comparing a viscoelastic assay to conventional coagulation assays. Ann Surg 2016; 263: 1051-9

54 Baksaas-Aasen K, Gall L, Eaglestone S, et al. ITACTIC implementing treatment algorithms for the correction of trauma-induced coagulopathy: study protocol for a multicentre, randomised controlled trial. Trials 2017; 18: 486.

55 Holcomb JB, Minei KM, Scerbo ML, et al. Admission rapid thrombelastography can replace conventional coagulation tests in the emergency department: experience with 1974 consecutive trauma patients. Ann Surg 2012; 256: 476-86. 


\section{ORIGINAL ARTICLES}

o JS, Christiaans SC, Stanworth SJ, et al. Detection of acute traumatic coagulopathy and massive transfusion requirements by means of rotational thromboelastometry: an international prospective validation study. Crit Care 2015; 19: 97

57 Meyer MA, Ostrowski SR, Sorensen AM, et al. Fibrinogen in trauma, an evaluation of thrombelastography and rotational thromboelastometry fibrinogen assays. J Surg Res 2015; 194: 581-90.

58 Meyer AS, Meyer MA, Sorensen AM, et al. Thrombelastography and rotational thromboelastometry early amplitudes in 182 trauma patients with clinical suspicion of severe injury. J Trauma Acute Care Surg 2014; 76: 682-90.

59 Wikkelso AJ, Edwards HM, Afshari A, et al. Pre-emptive treatment with fibrinogen concentrate for postpartum haemorrhage: randomized controlled trial. $\mathrm{Br} /$ Anaesth 2015; 114: 623-33.

60 Rahe-Meyer N, Levy JH, Mazer CD, et al. Randomized evaluation of fibrinogen vs placebo in complex cardiovascular surgery (REPLACE): a double-blind phase III study of haemostatic therapy. Br J Anaesth 2016; 117: 41-51.

61 Beyerle A, Nolte MW, Solomon C, et al. Analysis of the safety and pharmacodynamics of human fibrinogen concentrate in animals. Toxicol Appl Pharmacol 2014; 280: 70-7.

62 Solomon C, Groner A, Ye J, Pendrak I. Safety of fibrinogen concentrate: analysis of more than 27 years of pharmacovigilance data. Thromb Haemost 2015; 113: 759-71.

63 Schochl H, Nienaber U, Hofer G, et al. Goal-directed coagulation management of major trauma patients using thromboelastometry (ROTEM)-guided administration of fibrinogen concentrate and prothrombin complex concentrate. Crit Care 2010; 14: R55.
64 Lin DM, Murphy LS, Tran MH. Use of prothrombin complex concentrates and fibrinogen concentrates in the perioperative setting: a systematic review. Transfus Med Rev 2013; 27: 91-104.

65 Schlimp CJ, Ponschab M, Voelckel W, et al. Fibrinogen levels in trauma patients during the first seven days after fibrinogen concentrate therapy: a retrospective study. Scand J Trauma Resusc Emerg Med 2016; 24: 29.

66 Eldridge SM, Chan CL, Campbell MJ, et al. CONSORT 2010 statement: extension to randomised pilot and feasibility trials. BMJ 2016; 355: i5239.

67 Schochl H, Nienaber $U$, Maegele $M$, et al. Transfusion in trauma: thromboelastometry-guided coagulation factor concentrate-based therapy versus standard fresh frozen plasma-based therapy. Crit Care 2011; 15: R83.

68 Fenger-Eriksen $C$, Lindberg-Larsen $M$, Christensen $A Q$, et al. Fibrinogen concentrate substitution therapy in patients with massive haemorrhage and low plasma fibrinogen concentrations. Br J Anaesth 2008; 101: 769-73.

69 Jensen NH, Stensballe J, Afshari A. Comparing efficacy and safety of fibrinogen concentrate to cryoprecipitate in bleeding patients: a systematic review. Acta Anaesthesiol Scand 2016; 60: 1033-42.

70 Curry N, Hopewell S, Doree C, et al. The acute management of trauma hemorrhage: a systematic review of randomized controlled trials. Crit Care 2011; 15: R92.

71 Stanworth SJ, Hunt BJ. The desperate need for good-quality clinical trials to evaluate the optimal source and dose of fibrinogen in managing bleeding. Crit Care 2011; 15: 1006.

72 Winearls J, Campbell D, Hurn C, et al. Fibrinogen in traumatic haemorrhage: a narrative review. Injury 2017; 48: 230-42. 